\title{
The health and visibility cost of air pollution: a comparison of estimation methods
}

\author{
Mark A. Delucchi ${ }^{\dagger}$, James J. Murphy ${ }^{\ddagger}$ and Donald R. McCubbin ${ }^{\S}$ \\ † Institute of Transportation Studies, University of California Davis, CA 95616, USA \\ $\ddagger$ Department of Resource Economics and Center for Public Policy and Administration, University \\ of Massachusetts, Amherst, MA 01003, USA \\ $\S$ Abt Associates Inc., Bethesda, MD 20814, USA
}

Received 27 March 2000; accepted 7 September 2001

\begin{abstract}
Air pollution from motor vehicles, electricity-generating plants, industry, and other sources can harm human health, injure crops and forests, damage building materials, and impair visibility. Economists sometimes analyze the social cost of these impacts, in order to illuminate tradeoffs, compare alternatives, and promote efficient use of scarce resource. In this paper, we compare estimates of the health and visibility costs of air pollution derived from a meta-hedonic price analysis, with an estimate of health costs derived from a damage-function analysis and an estimate of the visibility cost derived from contingent valuation. We find that the meta-hedonic price analysis produces an estimate of the health cost that lies at the low end of the range of damage-function estimates. This is consistent with hypotheses that on the one hand, hedonic price analysis does not capture all of the health costs of air pollution (because individuals may not be fully informed about all of the health effects), and that on the other hand, the value of mortality used in the high-end damage function estimates is too high. The analysis of the visibility cost of air pollution derived from a meta-hedonic price analysis produces an estimate that is essentially identical to an independent estimate based on contingent valuation. This close agreement lends some credence to the estimates. We then apply the meta hedonic-price model to estimate the visibility cost per kilogram of motor vehicle emissions.
\end{abstract}

(C) 2002 Elsevier Science Ltd.

Keywords: economics, air pollution, health effects, visibility, environmental policy, motor vehicle emissions.

\section{Introduction}

Air pollution from motor vehicles, electricitygenerating plants, industry, and other sources, natural and man-made, can harm human health, injure crops and forests, damage building materials, and impair visibility. To mitigate these harms, the US Environmental Protection Agency (USEPA) sets standards for the maximum concentration of pollutants in the air (USEPA, 1998), and for the maximum rate of emissions from major sources such as motor vehicles and power plants. Because the USEPA's air quality and emissions standards can require costly changes in activities, processes,

\footnotetext{
*Corresponding author. Email: madelucchi@ucdavis.edu
}

and technologies, interest groups and legislators argue a great deal about what the standards should be, or whether we should complement or replace the standards with other approaches, such as emission pricing or emission trading. In order to evaluate and compare air quality standards, emission controls, new technologies (such as electric vehicles), and planning and pricing policies, economists sometimes analyze the relevant social costs and benefits, on the presumption that one should not adopt standards, controls, technologies, or policies whose social costs exceed social benefits (Schwing et al., 1980; Krupnick and Portney, 1991; Hall et al., 1992; Mayeres et al., 1996; USEPA, 1997; Kazimi, 1997; Borger and Wouters, 1998; Romilly, 1999; Johnston and Rodier, 1999; Funk and Rabl, 1999). 
Most such analyses of the social cost of air pollution employ a multi-step damage-function (DF) method, in which one estimates the relationships between policy and emissions, emissions and air quality, air quality and exposure, exposure and physical damage, and physical damage and monetary value (Delucchi, 2000). However, all of these steps - and the valuation step in particular-are uncertain, and as a result, estimates of the social cost of air pollutant emissions have proven to be highly variable, often differing by an order of magnitude or more (Murphy and Delucchi, 1998; McCubbin and Delucchi, 1999).

Given the potential importance of social-cost analysis to policy making, this uncertainty in the estimates is unsettling. Although we can expect that further research will narrow the uncertainty, we would in the meantime like to know whether these damage function estimates are credible, and which assumptions and results are likely to be most reasonable. Towards this end, we offer a modest check on the estimates of the cost of both the health and visibility effects of air pollution. We develop a meta-hedonic price analysis (meta-HPA), based on Smith and Huang (1995), to estimate a relationship between housing prices and housing attributes, including air quality. Because it is difficult, on the basis of HPA alone, to disentangle the health and visibility components of air quality, we make some reasonable assumptions about the allocation of these costs. We then compare these HPA estimates of the health and visibility costs with estimates we derive from alternative models. For health effects, we compare our meta-HPA estimates with recent DF estimates by McCubbin and Delucchi (1999); for visibility effects, we compare our meta-HPA estimates with the results of a simple contingent valuation model (CVM) proposed by Chestnut and Dennis (1997).

Although HPA has shortcomings itself, it is strongest where the DF approach arguably is weakest - in valuation. If carefully applied, it can offer a useful check on the DF results. As explained below, we expect the HPA estimate of the health costs of air pollution to lie at the low end of our DF-estimated range, and the HPA estimate of the visibility cost of air pollution to be of similar magnitude to the estimate based on a meta-CVM. This is just what we find, and we conclude that the health costs of air pollution are likely to lie towards the low end of our DF estimates, but above our HPA estimate, and that our estimates of visibility costs are reasonable.

In the paper, we begin with a discussion of the meta-HPA model and our estimates of the health and visibility costs. The subsequent section outlines our DF estimates of the health costs, followed by our meta-CVM estimates of the visibility costs. We conclude the paper with an application: an estimate of the visibility cost per kilogram of pollution from motor vehicles.

\section{A hedonic price estimate of the cost of air pollution}

\section{Overview}

In hedonic price analysis (HPA), developed theoretically by Rosen (1974), one estimates a marginal willingness-to-pay (MWTP) function on the basis of an estimated relationship between housing prices and housing attributes, including air quality. This approach thus attempts to capture the actual value that people place on air quality as revealed by their willingness-to-pay more for homes with better air quality, all else equal.

The strength of HPA is that it is based on real, revealed trade-off behavior in the market place. HPA's strength in the valuation step complements this weakness in DF estimates, making it a good tool for cross-checking these estimates. However, HPA has several weaknesses of its own (Cropper and Oates, 1992). First, the individual items being valued, such as air quality, are not marketed explicitly as separate items, but rather are marketed implicitly, as part of a bundle of many attributes. An analyst can estimate an implicit relationship between housing price and air quality, but because nobody trades air quality, the analyst cannot be sure that his measure of air quality is the one that people actually use. Ideally, one would use as an explanatory variable the measure of air quality that people actually have in mind when they buy a house. To the extent that the air quality explanatory variable in a hedonic model is not correlated with the real air quality variables in people's minds, the model will misestimate the relationship between housing value and air quality.

Most likely, prospective homebuyers judge air quality on the basis of whether or not the air appears polluted, and what people and the media say about the local air pollution. If this is so, then visual range, or some close proxy, such as total suspended particles (the measure used by Smith and Huang, 1995, in the model we apply below) is probably a reasonable representation of air quality as perceived and evaluated by people. 
More importantly, though, on the basis of HPA alone, an analyst cannot determine the components of the implicit value of air quality - health, visibility, soiling, etc. - because there are no separate indicators of these effects in the HPA. And perhaps most seriously, with respect to health effects, it is not clear the extent to which individuals are fully and correctly informed about the health impacts of air pollution. Individuals who underestimate the health effects of air pollution are willing to pay less of a premium for cleaner air than they would if they were fully informed. This last problem-imperfect information about the health effects of air pollution - has led some researchers to suggest that HPA underestimates the true health cost of air pollution (Harrison and Rubinfeld, 1978; Smith and Huang, 1995; Cropper, 2000). We think that this is broadly correct, although we do not have a good sense of just how under-informed people might be.

There are other reasons, probably not as important, why HPA might underestimate the true health cost of air pollution. The use of property value differences to estimate the benefits of air quality usually assumes that prices and quantities of other things are not affected by changes in air quality. If this assumption is violated, the change in property values may not reflect the household's full WTP for air quality, because people may respond to changes in air quality in ways that do not affect the value of their residences but affect the value of other goods. For example, the demand for some outdoor activities, such as golfing and jogging, may be affected by changes in air quality and cause changes in the prices of goods associated with these activities. If this occurs to any great extent, then HPA can capture only part of the benefits of a change in air quality. Our sense, though, is that this effect is minor.

Finally, HPA reflects WTP for air quality only in the areas of the housing markets included in the analysis; it does not capture the value of air quality outside of these areas. We believe that this omission matters a lot in the valuation of visibility, but very little in the valuation of health effects. Undoubtedly, people place a great deal of value on visibility in national parks and other scenic rural areas outside of housing in the air basin in which they live. However, to a first approximation, the probability of being made ill by air pollution is proportional to the time of exposure, and since most people probably spend at least $90 \%$ of their time in the air basin of their home, pollution outside of their air basin will have relatively little effect on their health. Therefore, we do not make any adjustments to the HPA results to account for the health cost of exposure to air pollution outside of the air basins where people live (and work). However, when we apply the HPA model to estimate the total national visibility cost per $\mathrm{kg}$ of emission from motor vehicles, we $d o$ need to adjust the results to account for WTP for visibility outside of the home regions. We discuss this adjustment briefly below. When we compare the CVM with the HPA, for the purpose of determining the credibility of the different estimation methods, we do not need to adjust the HPA, because the CVM also is WTP for visibility in the areas in which people live. Each method has its limitations (e.g. hedonic models estimate the value of goods that are not marketed explicitly, and CVM is prone to hypothetical bias), but we do not expect these weaknesses to yield major differences. Therefore, we check to see whether the visibility cost estimates from CVM and HPA are of similar magnitude. Although similar results do not necessarily imply that the two estimates are correct, we think it more likely that two dissimilar methods would give different wrong answers than the same wrong answer.

In the following section, we apply a metaanalysis of prior HPAs, by Smith and Huang (1995) to estimate the national cost of air pollution as revealed in the housing market. Where appropriate, we use the same county data sets and methods as we used in the DF analysis. We then refer to other studies to apportion the estimated total cost into health, visibility, and other components. Assuming that, on average, individuals tend to be under-informed about all of the health effects of air pollution, we expect (and indeed find) the HPA results to be at the low end of the DF results. ${ }^{1}$ We also compare the meta-HPA estimate of visibility costs with an independent meta-CVM estimate, and find close agreement.

\footnotetext{
${ }^{1} \mathrm{~A}$ number of studies suggest that although people may be acutely aware of, and concerned about, health risks from pollution, the public may not be educated enough about the causes or consequences of these risks to accurately incorporate these risks into property values. For example, in a survey of French physicians, Rotily et al. (1999) find that there is a need for improving the education of physicians about air pollution. Cropper (2000) asserts that it is unlikely that individuals are very well-educated about the health risks of dirty air. She notes that it is more likely that the property values used in HPAs capture all of the aesthetic benefits (e.g. visibility), but only capture a portion of the health benefits. Zabel and Kiel (2000) note that it is still unclear how individuals process air quality information when determining their willingness-to-pay for housing.
} 


\section{A meta-HPA of the cost of air pollution}

Smith and Huang (1995) perform a meta-analysis of prior meta-HPAs of the MWTP to reduce particulate matter levels. They review over 50 studies developed between 1967 and 1988, 37 of which had some empirical estimates involving hedonic price functions with some measure of air pollution. From the 167 hedonic models in these studies, Smith and Huang (1995) reconstruct 86 estimates of the MWTP for reducing total suspended particulates (TSP). They then estimate the relationship between MWTP, expressed for each study as the change in the asset value of a house per microgram per cubic meter $\left(\mu \mathrm{g} / \mathrm{m}^{3}\right)$ of TSP pollution, in each study, and several independent variables, including: the level of pollution in each city in the year closest to the date of the sample, real per-capita income in each city in the year closest to the date for the housing prices, the vacancy rate for the year closest to the date of the housing sales, and qualitative variables describing the characteristics of each study, such as the number of variables used to describe neighborhood quality.

Smith and Huang (1995) use two different estimators in their meta-analysis: minimum absolute deviation (MAD) and ordinary least squares (OLS). For each of the two estimators, they specified a simple model, in which TSP levels and per-capita income are the only independent variables, and a more comprehensive model, which included the vacancy rate, characteristics of the original studies, and other variables as well as pollution and income.

We have chosen the Smith and Huang (1995) meta-analysis over other studies because a metaanalysis, being a synthesis of many different studies from many different regions, is a better basis for estimating national damages. As Smith and Huang note, it is better to use a model that relates MWTP to pollution and income in each city than to pick a single best-guess MWTP for every city. We choose their simple MAD model because we have data on income and TSP levels in every county in the US, and because MAD is less sensitive to outlying observations, which are a concern in Smith and Huang's meta-analysis.

\section{A hedonic model of the cost of air pollution}

We model 1990 conditions (air quality, emissions, income, and population), and express our results in 1991 dollars. To estimate the cost of pollution in the US, we begin with a simple MAD air quality demand equation, developed by Smith and Huang (1995) and discussed above. This equation estimates the marginal willingness-topay per household, in 1982-1984 dollars per $\mu \mathrm{g} / \mathrm{m}^{3}$ of TSP, as a function of the per-capita income and the TSP level:

$$
V^{83}=\beta_{0}+\beta_{1} \cdot T S P+\beta_{2} Y^{83}
$$

where $V^{83}$ is the shadow price of air pollution, that is, the change in the asset value of the house per unit of pollution (dollars per house per $\mu \mathrm{g} / \mathrm{m}^{3}$ ), in 1982-1984 prices; TSP denotes total suspended particulates $\left(\mu \mathrm{g} / \mathrm{m}^{3}\right) ; Y^{83}$ represents the average per-capita income in 1982-1984; and the regression coefficients, $\beta_{0}, \beta_{1}, \beta_{2}$ equal -49.31 , $-0.23,0.01$, respectively. Because the Smith and Huang (1995) model is estimated with 1982-1984 data (we assume 1983), we use actual 1990 income, but deflate it to what it would be at 1983 price levels using GNP implicit price deflators. This approach captures the effect of the real increase in per-capita income.

We treat equation (1) as the household demand function for TSP reductions. To calculate how much households in the US are willing to pay for an improvement in air quality $\left(V T^{91}\right)$, we integrate the household demand function between the two TSP levels, and multiply by all households in the US. We estimate the cost of all anthropogenic visibility pollution, and the cost of motor vehicle pollution as:

$$
\begin{aligned}
V T^{91}= & \sum_{c}\left(H _ { c } \cdot \int _ { P P _ { c } } ^ { P I _ { c } } \left(\beta_{0} \cdot K_{1}+\beta_{1} \cdot T S P_{c} \cdot K_{1}\right.\right. \\
& \left.\left.+\frac{K_{1}}{K_{2}} \cdot \beta_{2} \cdot Y_{c}^{90}\right) d T S P_{c}\right)
\end{aligned}
$$

where $V T^{91}$ is the total amount extra that all households in the US would have been willing to pay for their homes, if they had bought their homes outright in 1991, if TSP in each county were at the level represented by $P P$ instead of the level represented by $P I$; the subscript $c$ denotes counties in the US; $H_{c}$ is the number of households in county $c$ in the US in 1990 (Bureau of the Census, 1994); $K_{1}$ is the GNP implicit price deflator to estimate 1991 WTP given 1983 prices and equals 1.322; $K_{2}$

\footnotetext{
${ }^{2}$ Note that we apply the WTP function (equation (2)), which is based on the preferences of home buyers, to all households, including renters, even though the function might be different for renters perhaps because in general they care less about amenities of home, all else equal.
} 
is the GNP implicit price deflator to estimate 1990 income given 1983 prices and equals 1.264; $P P_{c}$ denotes what the TSP level in county $c$ would have been in 1990 given a reduction in emissions; $P I_{c}$ denotes the actual TSP level in county $c$ in 1990 (discussed below); and $Y_{c}^{90}$ is average annual per capita income in county $c$ in 1990 (Bureau of the Census, 1994).

Equation (2) is our cost model. Note that the estimated total willingness-to-pay, $V T^{91}$, represents a one-time payment for a commodity (i.e. a home) that lasts many years. To convert this one-time total WTP to an annualized payment, $V T^{91}$ must be amortized, or annualized, over the economic life of the home. This annualized payment, which we will denote $V A^{91}$, is equal to full asset value (or one-time payment, $V T^{91}$ ) multiplied by an annualization factor $(A F)$ :

$$
V A^{91}=V T^{91} \cdot \frac{i}{1-(1+i)^{-t}}
$$

where $V A^{91}$ is the annualized WTP of households, and the last term on the right-hand side is the $A F$. Assuming an annual interest rate, $i$, for home investments between 4 and 7 percent (based on historical real mortgage interest rates, Bureau of the Census, 1992), with a term, $t$, of 40 to 30 years (our assumption), the annualization factor is 0.0505 in the low case, and 0.0806 in the highcost case.

\section{Estimating TSP levels}

The WTP model derived in (2) estimates the total annual household WTP for a change in TSP from the actual TSP level in 1990 to the TSP level after an assumed change in emissions (i.e. the elimination of all anthropogenic emissions). We specify the initial pollution level, PI, to be the actual ambient air quality in each county in the US in 1990. We estimate $P P$, in each county, on the assumption that the ratio of actual $P P$ to actual $P I$ is equal to the ratio of the modeled $P P$ to modeled $P I$ :

$$
\text { assume: } \frac{P P}{P I}=\frac{P P^{*}}{P I^{*}} \rightarrow P P=P I \cdot \frac{P P^{*}}{P I^{*}}
$$

where $P P$ is the estimated actual TSP level after the change in emissions (in this case, eliminate all anthropogenic emissions); PI is the actual ambient TSP level in 1990 prior to the change in emissions (data from air quality monitors, USEPA, 1993; see McCubbin and Delucchi, 1996, for details); $P P^{*}$ is the modeled level of TSP after the change in emissions (since we estimate the visibility cost of all anthropogenic TSP pollution, $P P^{*}$ is the natural, or background, level; see Delucchi and McCubbin, 1996, for details) ${ }^{3}$; and $P I^{*}$ is the modeled level of ambient TSP prior to the change in emissions (Delucchi and McCubbin, 1996).

We use a Gaussian dispersion air-quality model, with simple two-or three-step atmospheric chemistry, to model the ratio $P P^{*} / P I^{*}$ (see Delucchi and McCubbin, 1996, for details). In essence, the air-quality model estimates changes in ambient concentrations of particulate matter (the ratio $\left.P P^{*} / P I^{*}\right)$ as a function of changes in emissions of particulate matter and particulate-matter precursors and other parameters. ${ }^{4}$ In this air-quality model, we specify emission and dispersion parameters to represent urban and suburban situations, because the hedonic price model presented above estimates the WTP for reductions in TSP levels in areas where people buy property. We also weight modeled ambient pollutant levels according to their contribution to light extinction (Delucchi et al., 1996) because, as mentioned above, we believe that individuals really use visual range, not TSP levels per se, as the basis of assessing air pollution. Also, the use of lightextinction weights is appropriate when using the meta-HPA to estimate the visibility cost of air pollution.

\section{Apportioning the total WTP to health, visibility, and other components}

When people pay more for a house in an area with cleaner/clearer air, what benefits do they think that they are buying? Better health? Reduced soiling of clothes and materials? Or just better visibility? Certainly, we cannot assume that the air quality measured in the hedonic model that we use is valued only with respect to visibility or aesthetics per se, and not at all with

\footnotetext{
${ }^{3}$ We note that some of the TSP values that we use might be above or below the range of TSP experienced in the housing areas studied in the original hedonic price analyses. We assume that WTP in these extreme TSP ranges still is represented well by equation (2), even though equation (2) was not estimated in the range of the extreme values.

${ }^{4}$ TSP includes particulate matter greater than 10 microns in diameter $\left(\mathrm{PM}_{10}\right)$. However, because we do not have data on emissions of particles larger than $\mathrm{PM}_{10}$, we estimate TSP levels $\left(P P^{*} / P I^{*}\right)$ on the basis of $\mathrm{PM}_{10}$ emissions. (Hence the use of $\mathrm{PM}_{10}$ in Tables 1 and 2.) We assume that the ratio $P P^{*} / P I^{*}$ based on the available $\mathrm{PM}_{10}$ emissions data is similar to the ratio $P P^{*} / P I^{*}$ that would be derived based on TSP emissions were the TSP data available. We note also that combustion sources emit essentially no PM larger than $\mathrm{PM}_{10}$, and that PM larger than $\mathrm{PM}_{10}$ does not affect visibility appreciably.
} 
respect to human health, soiling, and so on - even if people are judging air quality on the basis of visibility, which seems likely. People undoubtedly know that the pollutants that cause haze and reduce visibility also harm persons, plants, animals, and materials. We suspect that most people use visibility as an indicator for a variety of effects - but which effects, and with what importance?.

In a CV study of the benefits of pollution control in the South Coast Air Basin of California, Brookshire et al. $(1979$; 1982) found that, of the estimated total willingness-to-pay for improved air quality, about $34 \%$ was for improved aesthetics, which we would call visibility per se. The remaining $66 \%$ was for improved health. Similarly, in a CV study in the western San Francisco Bay area in 1980, Loehman et al. (1994) found that for the average person in the area, the bid to avoid a loss of nonpolluted visibility days was about two-thirds of the bid to avoid a loss of good health days, and the bid to obtain an increase in nonpolluted visibility days was about $10 \%$ of the bid to obtain an increase in good health days. Thus, in the Loehman et al. (1994) study, the value of visibility was $10 \%$ to $40 \%$ of the total health plus visibility value of air quality. Finally, in their survey of WTP to improve air quality in Chicago and Atlanta, McClelland et al. (1991), found that $19 \%$ of the total WTP was for visibility per se, $49 \%$ was for health, $22 \%$ was for soiling, and $11 \%$ was for other impacts.

If home buyers nationally are similar to the persons who responded to the surveys of Brookshire et al., 1979; 1982, McClelland et al. (1991), and Loehman et al. (1994), and if the evaluation of air quality explicit in these surveys is similar to the evaluation implicit in the choice of a home, then we may apply these survey findings to the hedonic study of Smith and Huang (1995). Thus, we assume that value of visibility per se constitutes $15 \%$ to $35 \%$, and the value of health per se $50 \%$ to $70 \%$, of the total value of air quality estimated by the Smith and Huang (1995) meta-HPA. (Obviously, the $35 \%$ and the $70 \%$ high ends cannot both be true.)

Table 1 shows that the total cost of anthropogenic TSP pollution in residential areas, according to the meta-HPA used here, is on the order of US $\$ 52$ to US\$ 88 billion in 1990 (1991 \$). Assuming, as previously discussed that health is 50 to $70 \%$ of the total, and visibility represents 15 to $35 \%$ of the total, then the total health cost is US\$ 26 to US $\$ 61$ billion, and the total visibility cost is US\$ 8 to US $\$ 31$ billion.
Table 1. The health and visibility cost of anthropogenic TSP emissions, in air basins in which people live, as estimated by hedonic price analysis (billion $1991 \$$ in the year 1990)

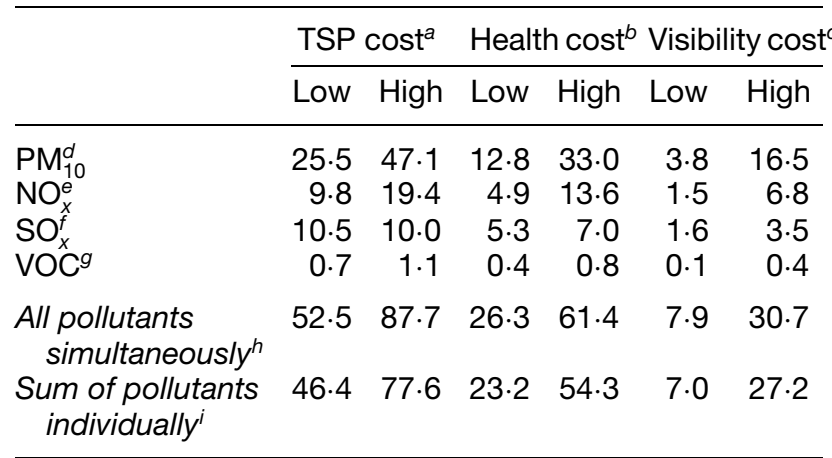

Note that the year of the analysis is 1990 (i.e. 1990 data for emissions, air quality, and income), but the year of the dollars is 1991. The estimates do not account for pollution outside of air basins in which people live. See the text for further details. TSP $=$ total suspended particulates.

${ }^{a}$ This is the total annualized household WTP to eliminate anthropogenic TSP pollution - VA in equation (3).

${ }^{b}$ This is the annualized household health cost of anthropogenic emissions, equal to VA (equation 3 ) multiplied by the assumed health share of total costs.

${ }^{c}$ This is the annualized household visibility cost of anthropogenic emissions, equal to VA (equation 3) multiplied by the assumed visibility share of total costs.

${ }^{d}$ Includes fine PM (less than $2.5 \mu \mathrm{m}$ ) and coarse PM (between $2.5 \mu \mathrm{m}$ and $10 \mu \mathrm{m})$

${ }^{e}$ Includes $\mathrm{NO}_{2}$ weighted by its relative light-absorption effect, and particulate nitrate weighted by its relative light-scattering effect.

${ }^{f}$ Particulate sulfate weighted by its relative light-scattering effect. $g$ Secondary organic aerosol weighted by its relative lightscattering effect.

$h$ The effect of removing all pollutants at once.

${ }^{i}$ The sum of the effects of removing pollutants one by one. This is not the quite the same as the effect of removing all of them at once, because the damage function is nonlinear. The difference, however, is not great.

\section{A damage function estimate of the health cost of air pollution}

\section{Overview of the method}

McCubbin and Delucchi $(1996 ; 1999)$ use a multistep DF approach to estimate the health cost of actual air pollution levels in the US in 1990. They estimate health costs in every county of the US, as a function of the actual emissions, air quality, and population characteristics in each county. To estimate emissions, they start with the USEPA's official emission inventory system, and correct therein what they believe are over- or under-estimation errors (Delucchi and McCubbin, 1996). They use a basic Gaussian dispersion model with simple, two- or three-step atmospheric chemistry to model the relationship between changes in emissions and changes in air quality (Delucchi and McCubbin, 
1996). On the basis of an extensive review of the epidemiology literature, they establish doseresponse functions for carbon monoxide (CO), ozone $\left(\mathrm{O}_{3}\right)$, particulate matter (PM; includes sulfates, nitrates, organic aerosols, and other particulate matter), and nitrogen dioxide $\left(\mathrm{NO}_{2}\right)$ (McCubbin and Delucchi, 1996). Finally, they estimate the values for a variety of acute and chronic health effects, with special attention to the value of mortality, which naturally is one of the largest components of the social-cost analysis. In this respect, they distinguish pollution-related deaths whereby a few days or weeks of life are lost from pollution-related deaths whereby years of life are lost, and assign a much lower value to the former (McCubbin and Delucchi, 1996; 1999). They also distinguish immediate from delayed deaths, and discount the latter to a present value. ${ }^{5}$

McCubbin and Delucchi $(1996 ; 1999)$ estimate the health cost of small changes in air pollution (specifically, the cost of a 10\% change in emissions related to motor vehicle use) and the total health cost of all anthropogenic air pollution. For the purposes of comparing DF results with HPA results, we use here their estimates of the total health cost of anthropogenic air pollution, because (1) it is an intuitively clear metric, and (2) the nonlinearities in both estimation methods (DF and HPA) are modest enough that the results of the comparison do not depend appreciably on the magnitude of the change in pollution (Delucchi et al., 1996; McCubbin and Delucchi, 1996; 1999). We compare estimates for the entire United States, rather than for particular regions, in order to be as general as possible. (We emphasize that, in both methods, our national totals are built up from county-specific estimates, and are not the result of generic national-level input assumptions).

\section{DF estimates of the total cost of anthropogenic air pollution}

Using a multi-step DF approach, McCubbin and Delucchi $(1996$; 1999) estimate that the total cost of anthropogenic air pollution in the US in 1990 was US\$ 55 to US\$ 670 billion (1991 dollars).

\footnotetext{
${ }^{5}$ McCubbin and Delucchi $(1996 ; 1999)$ assume that acute harvest deaths, i.e. immediate deaths, are 25\% (upper-bound cost case) to $50 \%$ (lower-bound cost case) of total time-seriesestimated acute deaths. Recent work by Schwartz (2000, 2001) is broadly consistent with these estimates. His work suggests that harvesting does not play a major role, and that most deaths are advanced from months to years, rather than the few days suggested by the harvesting hypothesis.
}

Ambient PM, including sulfates, nitrates, and organic aerosols, accounts for about $95 \%$ of the total damage cost, and mortality related to ambient PM accounts for about $70 \%$ of the total damage cost. Thus, assumptions about the relationship between $\mathrm{PM}$ and mortality, and about the value of mortality, strongly determine the overall cost estimates. ${ }^{6}$ And the considerable uncertainty in these two relationships - at least a factor of two difference between the low and the high estimates of PM mortality, and at least a factor of 4 difference between the low and the high assumptions for mortality valuation (McCubbin and Delucchi, 1996)-leads to great uncertainty in the total cost estimate, as manifested by the order-of-magnitude difference between the low estimate of US $\$ 55$ billion and the high estimate of US $\$ 670$ billion.

The differences between the estimates of $\mathrm{McCub}$ bin and Delucchi (1996; 1999), and those made by Krupnick and Portney (1991), Hall et al. (1992), and Small and Kazimi (1995), can be explained largely by different assumptions regarding the number of deaths attributable to PM pollution, and the value of those deaths. For the value of a statistical life, Hall et al. (1992) assume a range of US\$ 1.8 to US\$ 9.2 million, Small and Kazimi (1995) a range of US\$ 2.0 to US\$ 11.0 million, and Krupnick and Portney (1991) a value of US $\$ 1.0$ million (on the presumption that air pollution kills old and sick person with a low value of life). In a survey of 26 studies (21 labor market studies, 5 contingent valuation studies), the USEPA found that the average value of a statistical life was US\$ 4.8 million in 1990 dollars (USEPA, 1999). McCubbin and Delucchi $(1996 ; 1999)$ use a range of US\$ 0.01 to US\$ 0.05 million for air-pollutionrelated deaths that would have occurred very soon anyway, had there been no pollution, and US $\$ 1.0$ to US $\$ 4.0$ million for deaths that would not have occurred soon (McCubbin and Delucchi, 1996). In these studies, there also are large differences in

${ }^{6}$ More generally, some of the key assumptions behind our damage function estimates include:

(i) applying the results of epidemiological studies to the entire population of the US, assuming that the conditions in each study are relevant to all persons in the US.

(ii) assessing the relative potency of particulates based on size and source, e.g. that those emitted by motor vehicles are relatively more potent than soil-based particulates. While recent work by Schwartz suggests that they are indeed more potent, the epidemiological literature is still far from clear on the relative potency of different types.

(iii) assuming that people's WTP is invariant to the amount of risk reduction already purchased. A more realistic assumption would be a declining marginal WTP. 
the estimates of the number of deaths related to PM pollution.

In the recent ExternE project, an analysis of the external costs of air pollution from power plants and motor vehicles in Europe, the problem of valuing a statistical life is analyzed in two parts: the number of life-years lost due to air pollution, multiplied by the value of a life-year lost (Spadaro et al., 1998; Funk and Rabl, 1999; Rabl and Spadaro, 1999). However, in the ExternE analysis, the number of life years lost either is assumed or else is estimated on the basis of the Pope et al. (1995) cohort epidemiology study, and the value of a life-year is estimated on the basis of a mid-range assumption regarding the value of a statistical life (about US\$ 3 million). Hence, although uncertainty in ExternE in the key assumptions is split into different components, the uncertainty is not eliminated or even substantially reduced.

There is, however, some indication that the statistical value of a life or life-year is less likely to be near the higher end of the ranges typically used, and that the lower and mid-range estimates may be more plausible. Air pollution mortality occurs mainly among the elderly: three-quarters of the statistical lives saved from the Clean Air Act are persons aged 65 and over (USEPA, 1997). Although there are few estimates of the value of a statistical life specifically for the elderly, there are some indications that the value of a life-year for the elderly may be lower than those of the young. One study that does estimate WTP by age for reductions in mortality risk is Krupnick et al. (2000). Using a CVM survey in Hamilton, Ontario, they find WTP does not vary much by age and remains relatively constant until about age 70 , but then decreases by about one-third for individuals over 70. Cropper (2000) notes that simulations of the life-cycle consumption model of Yaari (1965) suggest that WTP for reductions in the risk of death are lower at age 60 than at 40 , and this result is confirmed by Jones-Lee et al. (1985). Johannesson and Johansson (1997) asked persons of varying ages their willingnessto-pay (WTP) today for a medical treatment at age 75 that would increase their life expectancy thereafter from 10 to 11 years. The average WTP was an order of magnitude lower, at least, than the value of life typically derived from contingent valuation and wage-risk studies. Johannesson and Joahnsson (1997) believe that the value is so low because the respondents expect that their quality of life at age 85 or 86 will be relatively poor, and because the extra year is 35 to 40 years down the road. $^{7}$

The upshot of this is that much uncertainty remains in the valuation step in DF analysis of the mortality costs of air pollution, particularly in the value of a statistical life by age, but that there is some indication that the higher values should be probably be avoided. As a modest check on this hypothesis, and on the overall credibility of the DF approach, we now compare our DF results with our HPA results.

\section{DF health-cost results and a comparison with HPA estimates}

The health cost of US $\$ 26$ to US $\$ 61$ billion estimated by the meta-HPA (Table 1), lies at the low end of the US\$ 55 to US\$ 670 billion range of health costs estimated by the DF method and discussed above. This is consistent with our beliefs that: (i) the housing market does not capture the full cost of the health effects of air pollution, primarily because people are not well-educated about all of these; and (ii) the mortality valuation assumptions that lead to the upper end of the DF range may be too high.

We emphasize that our results merely are consistent with both (i) and (ii) being true, but do not by themselves demonstrate that both (i) and (ii) are true. In the absence of any other theory or evidence, a result in which a meta-HPA estimate lies at the low end of a DF estimate can be explained by either (i) or (ii). However, we give independent reasons why both (i) and (ii) might be true, and then find that our results are not inconsistent with both being true. It could have been otherwise. For example, if the meta-HPA estimate were at the high end of the DF range, then it would be unlikely that both (i) and (ii) were correct. In that case, and in the (also not obtained) case in which the HPA estimates were much lower than the low end of the DF range, we would have less confidence that any estimates were credible. But given that our results are not inconsistent with our beliefs about the problems with the DF and HPA approaches, we conclude tentatively that DF analysis of the health costs of air pollution should be based on 'conservative' estimates of the value of a life-year lost to air pollution.

\footnotetext{
${ }^{7}$ An anonymous reviewer correctly notes that the Johannesson and Johansson (1997) results do not necessarily indicate what these individuals would be WTP once they actually reach age 75 .
} 


\section{A contingent valuation estimate of the visibility cost of air pollution}

\section{Overview}

In this section, we present a contingent-valuation estimate of the cost of visibility impairment due to air pollution, for comparison with our metaHPA-derived estimate. Most estimates of the cost of visibility impairment due to air pollution employ CV, in which researchers survey people and ask them to make explicit, but hypothetical, tradeoffs between visibility and dollars or goods with a known dollar value. The main strength of $\mathrm{CV}$ is that it is explicit: the item to be valued (in our case, visibility) is identified, described, and 'marketed' explicitly. In principle, one can perform a CV study of any nonmarket good, and one can value separately items that otherwise are difficult to disentangle: for example, the visibility and health effects of polluted air. Because they are hypothetical, CV studies are not limited by the availability of data from real markets. And because they explicitly ask for individual willingness-to-pay for specific goods or services, in principle they tell the costbenefit analyst precisely what she or he needs to know.

However, the obvious and potentially grave weakness of $\mathrm{CV}$ is that the valuation is hypothetical, and therefore reliable only insofar as people respond realistically to the hypothetical market (see Harrison and Rutström, 1999, for a survey of the hypothetical bias literature). Unfortunately, this difficulty becomes most serious in precisely those situations in which $\mathrm{CV}$ in principle is the most useful: the valuation of nonmarket goods and services that people apparently care about but have no experience valuing or trading. With CV studies, the challenge then is to design a credible scenario and market mechanism, to induce people to behave as realistically as possible. (See Chestnut and Rowe, 1990b; and McClelland et al., 1991, for further discussion of methodological issues. See Chestnut and Rowe, 1990a; Delucchi et al., 1996; and Chestnut and Dennis, 1997, for a review of the literature). We see, then, that CV and meta-HPA have complementary strengths and weaknesses: CV elicits explicit valuation, but in a hypothetical market, whereas HPA reveals implicit valuation in a real market. This makes it particularly interesting to compare estimates derived from the two methods.

\section{A meta-CVM function for WTP for changes in visibility}

Chestnut and Rowe (1990a) review the results of CVM studies of household WTP for visibility, and, develop the following function which puts the mean WTP results from different studies into a common metric:

$$
V A H H_{i}=\alpha \cdot \ln \left(\frac{V_{2 i}}{V_{1 i}}\right),
$$

where the subscript $i$ denotes geographic area; $V A H H_{i}$ is the annual WTP per household in area $i$ for visibility changes in that year; $V_{1 i}$ is the actual average annual visual range in area $i$ (miles); $V_{2 i}$ is the hypothetical alternative average annual visual range in area $i$ (miles); $l n$ is the natural $\log$; and $\alpha$ is an estimated coefficient (discussed below).

Note that equation (5), unlike equation (1), already is the annual household WTP for the entire change in visibility, not the change in house value per unit of pollution or visibility. Hence, we do not need to integrate this equation between visibility levels, and then annualize the results; rather, we simply insert the appropriate visual range values. The total national visibility cost is then equal to the cost per household multiplied by the number of households (assuming for the illustrative calculation to follow that the 'region' $i$ of interest is the entire US):

$$
V A_{U S}=H_{U S} \cdot V A H H_{U S}=H_{U S} \cdot \alpha \cdot \ln \left(\frac{V_{2 U S}}{V_{1 U S}}\right),
$$

where $V A_{U S}$ is the total national household WTP for the visibility change from $V_{1}$ to $V_{2}$; and $H_{U S}$ is the number of households in the US in 1990 (94.3 million households in the entire US in 1990; Bureau of the Census, 1992). Because it is difficult to obtain or estimate visibility data for every county in the US, we estimate the national visibility cost of air pollution on the basis of what we assume to be national-average parameter values, rather than as the sum of county costs estimated with county-specific values.

\section{The $\alpha$ coefficient}

Chestnut and Dennis (1997) select a value of 160 for the coefficient $\alpha$ (in $1994 \$$ ), on the basis of the fully adjusted results from CV studies of the value of visibility in Chicago and Atlanta by McClelland et al. (1991). This coefficient value of 160 corresponds to the McClelland et al. (1991) 
best estimate of the value of only visibility, after correcting for non-response and high-end bias. In 1991 dollars, the coefficient is 149 .

\section{Visual range}

The National Climatic Data Center (NCDC, 1991) provides hourly horizontal visual range for 187 sites in the US in 1990. Visual range is the median of the 365 calculated daily visibility values, in miles, where the daily visibility is calculated as the average of the visibility readings at 10:00 AM, 1:00 $\mathrm{PM}$, and 4:00 $\mathrm{PM}$ each day. Visual range typically is between 10 and 100 miles, and generally less than 50 miles. On the basis of the NCDC estimates, and data and estimates in Trijonis (1982, Ozkaynak et al. (1985), Watson and Chow (1994), and USEPA (1998), we assume a national-average actual visual range of 15 to 25 miles in $1990\left(V_{1}\right)$. We assume that in the absence of anthropogenic air pollution, $V_{2}$ would be 80 to 100 miles (USEPA, 1998; Watson and Chow, 1994).

\section{Illustrative calculation}

With the above assumptions, $V A_{U S}$ in equation (6) is US\$ 16 to US\$ 27 billion. (This, like the HPA estimate of visibility cost, does not include WTP to improve visibility outside of air basins in which people live.) This range of US $\$ 16$ to US $\$ 27$ billion is in the middle of the US\$ 8 to US $\$ 31$ billion range estimated by HPA (Table 1). Given the significant differences in approaches between the CVM and HPA, this close agreement lends some credence to the estimates, and gives us more confidence that it is reasonable to use these estimates in policy analysis. ${ }^{8}$ In the next section, we present and apply a useful social-cost metric that can be derived from our HPA of visibility costs.

\section{An application of the HPA estimates: the dollars-per- kilogram visibility cost of pollution from motor vehicles}

Motor vehicles are a primary source of PM, and hence a primary cause of visibility degradation.

\footnotetext{
${ }^{8}$ Put another way, the similarity of results is consistent with, but does not demonstrate, the proposition that both methods and sets of results are valid. Had the CVM results differed widely from the HPA results, we would have known that at least one of the methods and results were flawed, and hence could not have made any claim for either of the results being valid.
}

Although vehicle emissions are often the subject of intense regulatory debate and benefit-cost analyses, there are few, if any, credible estimates of the visibility costs of motor vehicle emissions. We can use the HPA model described above to estimate the visibility cost per unit of pollution from motor vehicles. The per-unit cost then can be applied to estimate the total cost of visibility pollution due to motor vehicle use.

The total cost of motor vehicle pollution can be estimated simply as the product of three terms: the dollar damage cost per unit of pollutant emitted (say, US $\$ / \mathrm{kg}$ ), units of pollutant emitted per mile of travel $(\mathrm{kg} / \mathrm{mi})$, and total miles of travel. Because data on emission factors $(\mathrm{kg} / \mathrm{mi})$ and miles of travel are widely available, the important contribution of a social-cost analysis is an estimate of the US $\$ / \mathrm{kg}$ damage. Thus, McCubbin and Delucchi (1999), Funk and Rabl (1999), and Small and Kazimi (1995) estimate the $\$ / \mathrm{kg}$ health-damage cost of motor vehicle emissions, and Murphy et al. (1999) estimate the $\$ / \mathrm{kg}$ crop-damage cost of motor vehicle emissions. In addition to these, it would be useful to have estimates of the $\$ / \mathrm{kg}$ visibility cost of motor vehicle emissions.

For this purpose of estimating the $\$ / \mathrm{kg}$ visibility cost of motor vehicle emissions, we use the meta-HPA of Smith and Huang (1995), rather than the CVM function of Chestnut and Dennis (1997), because the meta-HPA includes household income as well as air quality (TSP) as an explanatory variable and was estimated on the basis of a large number of studies, whereas the CVM function has only visual range as an explanatory variable and was specified according to the results of a CVM study for only two cities - Chicago and Atlanta (Chestnut and Dennis, 1997).

We use the simple air quality model described in Delucchi and McCubbin (1996) to determine the relationship between TSP air quality and a $10 \%$ reduction in motor vehicle emissions of PM and PM precursors in each county. This relationship allows us to estimate PP in equation (2), for each county. (Recall that PI are the actual TSP levels reported for each county). To produce a $\$ / \mathrm{kg}$ figure, we divide the total cost of the $10 \%$ reduction by the total amount of emissions reduced. This $\$ / \mathrm{kg}$ figure can be used with any assumed emission rate (in $\mathrm{kg} / \mathrm{mi}$ ) to produce an estimate of the damage cost per mile of travel.

Table 2 shows the visibility cost per $\mathrm{kg}$ of pollutant emission, for a $10 \%$ reduction in motor 
Table 2. The national visibility cost of a kilogram of emissions attributable to light-duty gasoline vehicles, heavy-duty diesel vehicles, and all motor vehicles, given a $10 \%$ reduction in emissions related to motor vehicle use $(1991 \$ / \mathrm{kg}$-emitted in the year 1990)

\begin{tabular}{|c|c|c|c|c|c|c|c|c|}
\hline \multirow[t]{2}{*}{ Emissions source } & \multicolumn{2}{|c|}{$\$ / k g-\mathrm{PM}_{10}^{a}$} & \multicolumn{2}{|c|}{$\$ / \mathrm{kg}-\mathrm{NO}_{x}^{b}$} & \multicolumn{2}{|c|}{$\$ / \mathrm{kg}-\mathrm{SO}_{x}^{c}$} & \multicolumn{2}{|c|}{$\$ / \mathrm{kg} \mathrm{VOCs}^{d}$} \\
\hline & Low & High & Low & High & Low & High & Low & High \\
\hline LDGAs & 0.58 & 4.09 & 0.22 & $1 \cdot 21$ & 1.35 & 5.00 & 0.01 & 0.04 \\
\hline LDGAs + U & 0.46 & 3.04 & 0.21 & 1.13 & 0.34 & 1.08 & 0.01 & 0.04 \\
\hline LDGAs+U+RDP & 0.33 & 1.92 & 0.21 & 1.13 & 0.34 & 1.08 & 0.01 & 0.04 \\
\hline $\mathrm{LDGAs}+\mathrm{U}+\mathrm{RDP}+\mathrm{RDU}$ & 0.09 & 0.74 & 0.21 & $1 \cdot 13$ & 0.34 & 1.08 & 0.01 & 0.04 \\
\hline HDDVs & 0.32 & 3.79 & 0.11 & 0.90 & 0.62 & 3.38 & 0.02 & 0.17 \\
\hline HDDVs+U & 0.31 & 3.69 & 0.11 & 0.87 & 0.43 & $2 \cdot 15$ & 0.01 & 0.10 \\
\hline HDDVs+U+RDP & 0.31 & $2 \cdot 25$ & 0.11 & 0.87 & 0.43 & $2 \cdot 15$ & 0.01 & 0.10 \\
\hline $\mathrm{HDDVs}+\mathrm{U}+\mathrm{RDP}+\mathrm{RDU}$ & 0.10 & 0.91 & 0.11 & 0.87 & 0.43 & $2 \cdot 15$ & 0.01 & $0 \cdot 10$ \\
\hline MVs & 0.40 & 3.90 & 0.19 & $1 \cdot 11$ & 0.89 & 3.97 & 0.01 & 0.05 \\
\hline $\mathrm{MVs}+\mathrm{U}$ & 0.37 & 3.47 & 0.17 & 1.04 & 0.36 & 1.35 & 0.01 & 0.04 \\
\hline $\mathrm{MVs}+\mathrm{U}+\mathrm{RDP}$ & 0.32 & 2.07 & 0.17 & 1.04 & 0.36 & 1.35 & 0.01 & 0.04 \\
\hline $\mathrm{MVs}+\mathrm{U}+\mathrm{RDP}+\mathrm{RDU}$ & 0.10 & 0.81 & 0.17 & 1.04 & 0.36 & 1.35 & 0.01 & 0.04 \\
\hline
\end{tabular}

$\mathrm{PM}_{10}=$ particulate matter of aerodynamic diameter of 10 microns or less; $\mathrm{NO}_{\mathrm{x}}=$ nitrogen oxides; $\mathrm{SO}_{\mathrm{x}}=$ sulfur oxides; VOCs $=$ volatile organic compounds; LDGAs=light-duty gasoline automobiles; HDDVs=heavy-duty diesel vehicles; MVs=motor vehicles; U=upstream; $\mathrm{RDP}=$ road dust from paved roads; $\mathrm{RDU}=$ road dust from unpaved roads. Note that in all cases, the year of the analysis is 1990 (i.e. 1990 data for emissions, air quality, and income), but the year of the dollars is 1991. The estimates do account for visibility costs outside of the air basins in which people live.

${ }^{a}$ Equal to the dollar cost of $10 \%$ of the primary ambient $\mathrm{PM}_{10}$ (weighted by its relative light extinction) attributable to motor vehicles, divided by $10 \%$ of $\mathrm{PM}_{10}$ emissions attributable to motor vehicles. Primary or direct PM is PM that is emitted as such, as distinguished from $\mathrm{PM}$ that is formed in the atmosphere.

${ }^{b} \mathrm{NO}_{\mathrm{x}}$ emissions can become ambient $\mathrm{NO}_{2}$ or form particulate nitrate aerosols. The $\$ / \mathrm{kg}$ estimate is equal to the dollar cost of $10 \%$ of the ambient $\mathrm{NO}_{2}$ and $10 \%$ of the ambient particulate nitrate (weighted by their relative light extinction) attributable to motor vehicles, divided by $10 \%$ of $\mathrm{NO}_{\mathrm{x}}$ emissions attributable to motor vehicles.

${ }^{c} \mathrm{SO}_{\mathrm{x}}$ emissions can form particulate sulfate aerosols, which scatter light and reduce visibility. The $\$ / \mathrm{kg}$ estimate is equal to the dollar cost of $10 \%$ of the ambient particulate sulfate (weighted by its relative light extinction) attributable to motor vehicles, divided by $10 \%$ of $\mathrm{SO}_{\mathrm{x}}$ emissions attributable to motor vehicles.

${ }^{d}$ VOC emissions can form secondary organic aerosols, which scatter light and reduce visibility. The $\$ / \mathrm{kg}$ estimate is equal to the dollar cost of $10 \%$ of the ambient organic aerosol (weighted by its relative light extinction) attributed to motor vehicles, divided by $10 \%$ of VOC emissions attributable to motor vehicles.

vehicle use. ${ }^{9}$ The estimates include the cost of visibility outside of air basins where people live, which, on the basis of the judgment of Chestnut and Rowe (1990a) and other sources cited in Delucchi et al. (1996), we estimate to be $40 \%$ to $70 \%$ of the costs estimated by the HPA. (The estimates also include a correction for negative values produced in the HPA; see Delucchi et al., 1996, for details). The results are shown for direct emissions from motor vehicles, motor vehicle emissions plus upstream emissions (e.g. from petroleum refineries making motor fuel), and motor vehicle plus upstream plus road-dust emissions.

Table 2 indicates that, per kilogram of emission, direct $\mathrm{PM}$ and $\mathrm{SO}_{\mathrm{x}}$ emissions have the largest visibility costs. The $\$ / \mathrm{kg}$ cost of $\mathrm{SO}_{\mathrm{x}}$ exceeds the $\$ / \mathrm{kg}$ cost of $\mathrm{NO}_{\mathrm{x}}$ because the fraction of $\mathrm{SO}_{\mathrm{x}}$ that becomes particulate sulfate (which causes the reduction in visibility) exceeds the fraction of $\mathrm{NO}_{\mathrm{x}}$ that becomes particulate

\footnotetext{
${ }^{9}$ Delucchi (2000) summarizes estimates of the $\$ / \mathrm{kg}$ cost of
} emissions from motor vehicles. nitrate (Delucchi and McCubbin, 1996). The $\$ / \mathrm{kg}$ cost of VOCs is so small because such a small fraction of VOC emissions becomes organic aerosol (which causes the reduction in visibility).

The $\$ / \mathrm{kg}$ cost including emissions from paved and unpaved roads is much smaller than the $\$ / \mathrm{kg}$ cost of vehicular tailpipe emissions only (or tailpipe plus upstream emissions) because particulate matter from vehicles and upstream sources generally is fine, whereas most road dust $\mathrm{PM}$ is coarse, and the light-extinction coefficient for coarse particles is much less than the coefficient for fine particles.

\section{The total visibility cost of motor vehicle use}

Delucchi (2000) summarizes estimates of the total social cost of motor vehicle pollution: US $\$ 24-450$ billion/year of health costs (including, in the high end, a somewhat speculative US\$ 154 billion of 
damages from road dust alone), US\$ 5-37 billion/year of visibility costs, US\$ 0.4-8 billion/year of material-damage costs, and US\$ 2-6 billion/year of damages to forests and crops. Visibility costs thus are about an order of magnitude smaller than health costs, but large enough absolutely to be worth estimating.

\section{Conclusions}

Public awareness and concern about the problems associated with reduced air quality have increased in recent years. Nevertheless, there still remains considerable uncertainty about both the severity and the valuation of these impacts. The valuation of environmental damages can play an important role in establishing environmental policy and regulatory standards, and can provide guidance in targeting mitigation efforts. In order to achieve environmental objectives at least cost, policymakers and managers need to balance the relevant social costs and benefits. Without reasonable estimates of these values, it is difficult, if not impossible, to formulate efficient environmental policies. The estimates of the health and visibility costs of air pollution can differ by an order of magnitude, and this can be disconcerting when these differences may be critical in deciding among policy options. Further research is necessary before this valuation uncertainty can be reduced. In the meantime, the goal of this paper is to determine whether the existing estimates are reasonable for use in decisionmaking, such as benefit-cost analysis, and to compare alternative methods of estimating these values.

When estimating the health costs of reduced air quality, premature mortality is not only one of the single largest cost components, but it is also one of the largest sources of uncertainty. Thus, it is hardly surprising that estimates can differ by an order of magnitude. The elderly are most likely to be affected by changes in air quality (USEPA, 1999), yet the average age in most wage-risk studies is closer to 40 . There is some evidence that the value of a statistical life for the elderly may be lower than that of younger individuals (Jones-Lee et al., 1985; Krupnick et al., 2000); the USEPA (1999) comments that the direction of this age bias is uncertain, but probably an overestimate. Damage-function estimates that do not account for differences in mortality values by age will tend to overestimate these costs, suggesting that the more conservative DF estimates are more reasonable. Meta-hedonic price analysis is not sensitive to assumptions about mortality costs and offers a natural complement to DF estimates. However, hedonic price analyses assume that individuals are fully informed about the relationship between air quality and health impacts. Although individuals may be aware that this relationship exists, it is less likely that they are educated enough to correctly incorporate this information into their pricing decisions for housing. To the extent that people underestimate this relationship, HPAs will tend to underestimate the health costs.

Our application of a meta-hedonic price analysis of the cost of air pollution produces an estimate of the health cost that lies at the low end of a range we estimate with the damage function approach. This is consistent with the hypothesis that damagefunction estimates will tend to overestimate the health costs (because mortality estimates may be too high), and HPAs will underestimate these costs (because individuals may not be well-educated about the health effects). We conclude that DF analyses of the health costs of air pollution should be based on conservative estimates of the value of a life-year lost to air pollution and should reflect the differences in the value of a life year for different age groups, particularly the elderly.

Non-market valuation techniques have played an increasingly important role in policy debates and have influenced regulatory decisions by the USEPA (Smith, 2000). Although significant progress has been made in refining these techniques, there is still considerable uncertainty regarding these values. We apply different, complementary valuation techniques to estimate the health and visibility costs of air pollution in the United States. Although the consistency of our results does not necessarily imply that they are accurate, it is reassuring that two independent estimates of these values generate consistent results. Moreover, we can draw an overall conclusion about validity of HPA. If on the one hand the HPA air quality estimate lies at the low end of the DF range - as we expect - and on the other the HPA visibility estimate is similar to the CVM visibility estimate, we can conclude tentatively that our understanding and interpretation of HPA results are reasonable. Until further research reduces the uncertainty surrounding existing estimates, our results suggest that these valuations are reasonable for use in policy analyses and management decisions. 


\section{Acknowledgements}

Support for the social-cost analysis was provided by Pew Charitable Trusts, the Federal Highway Administration (through Battelle Columbus Laboratory), the University of California Transportation Center, the University of California Energy Research Group (now the University of California Energy Institute), and the now-defunct US Congress Office of Technology Assessment. Thanks to Tom Stevens and three anonymous reviewers for comments that have improved the quality of this paper. Of course, we alone are responsible for the contents of this paper.

\section{References}

Borger, B. D. and Wouters, S. (1998). Transport externalities and optimal pricing and supply decisions in urban transportation: a simulation analysis for Belgium. Regional Science and Urban Economics 28, 163-197.

Brookshire, D. S., Crocker, T. D. and d'Arge, R. C. (1979). Methods Development for Assessing Air Pollution Control Benefits. EPA 600/5-79-001. Washington, DC: US Environmental Protection Agency.

Brookshire, D. S., Thayer, M. A., Schulze, W. D. and D'arge, R. C. (1982). Valuing public goods: a comparison of survey and hedonic approaches. The American Economic Review 72, 165-177.

Bureau of the Census (1992). Statistical Abstract of the United States. Washington, DC: US Department of Commerce.

Bureau of the Census (1994). USA Counties. A Statistical Abstract Supplement. CD-ROM c3.134/6. US Department of Commerce, Economics and Statistics Administration.

Chestnut, L. G. and Dennis, R. L. (1997). Economic benefits of improvements in visibility: acid rain provisions of the 1990 clean air act amendments. Journal of the Air and Waste Management Association 47, 395-402.

Chestnut, L. G. and Rowe, R. D. (1990a). Economic valuation of changes in visibility: a state of the science assessment for NAPAP. In Acid Deposition: State of Science and Technology, Report 27, Methods for Valuing Acidic Deposition and Pollution Effects. pp. 27-153 to 127-175. Washington, DC: National Acid Precipitation Assessment Program.

Chestnut, L. G. and Rowe, R. D. (1990b). Preservation Values for Visibility Protection at the National Parks. Research Triangle Park, NC: US Environmental Protection Agency, Office of Air Quality Planning and Standards, Economic Analysis Branch.

Cropper, M. L. (2000). Has economic research answered the needs of environmental policy? Journal of Environmental Economics and Management 39, 328-350.

Cropper, M. L. and Oates, W. E. (1992). Environmental economics: a survey. Journal of Economic Literature 30, 675-740.

Delucchi, M. A. (2000). Environmental externalities of motor vehicle use in the US. Journal of Transport Economics and Policy 34, 135-168.
Delucchi, M. A. and McCubbin, D. C. (1996). The Contribution of Motor Vehicles and Other Sources to Ambient Air Pollution. UCD-ITS-RR-96-3(13). Davis, CA: University of California, Institute of Transportation Studies. August.

Delucchi, M. A., Murphy, J., McCubbin, D. R. and Kim, J. (1996). The Cost of Reduced Visibility Due to Particulate Air Pollution from Motor Vehicles. UCDITS-RR-96-3(13). Davis, CA: University of California, Institute of Transportation Studies. August.

Funk, K. and Rabl, A. (1999). Electric versus conventional vehicles: social costs and benefits in France. Transportation Research D 4, 397-411.

Hall, J. A. et al. (1992). Valuing the health benefits of clean air. Science 255, 812-817.

Harrison, D. and Rubinfeld, D. L. (1978). Hedonic housing prices and the demand for clean air. Journal of Environmental Economics and Management 5, 81-102.

Harrison, G. W. and Rutström, E. E. (1999). Experimental evidence on the existence of hypothetical bias in value elicitation methods. Draft book chapter. In Handbook of Results in Experimental Economics, To be published in (C. Plott and V. L. Smith, eds), Elsevier Science Ltd, forthcoming.

Johannesson, M. and Johansson, P. (1997). Quality of life and the WTP for an increased life expectancy at an advanced age. Journal of Public Economics 65, 219-228.

Johnston, R. A. and Rodier, C. J. (1999). Synergisms among land use, transit, and travel pricing policies. Transportation Research Record 1670, 3-7.

Jones-Lee, M. W., Hammerton, M. and Philips, P. R. (1985). The value of safety: results of a national sample survey. The Economic Journal 95, 49-72.

Kazimi, C. (1997). Evaluating the environmental impacts of alternative-fuel vehicles. Journal of Environmental Economics and Management 33, 163-185.

Krupnick, A. D. et al. (2000). Age, Health, and the Willingness to Pay for Mortality Risk Reductions: A Contingent Valuation Survey of Ontario Residents. Discussion paper 00-37. Washington, DC: Resources for the Future.

Krupnick, A. and Portney, P. R. (1991). Controlling urban air pollution: a benefit cost assessment. Science $\mathbf{2 5 2}$, $522-528$

Loehman, E. T., Park, S. and Boldt, D. (1994). Willingness-to-pay for gain and losses in visibility and health. Land Economics 70, 478-498.

Mayeres, I., Ochelen, S. and Proost, S. (1996). The marginal external costs of urban transport. Transportation Research 1D, 111-130.

McClelland, G. et al. (1991). Valuing Eastern Visibility: A Field Test of the Contingent Valuation Method. USEPA Cooperative Agreement \#CR815183-01-2. Washington, DC: US Environmental Protection Agency, Office of Policy, Planning, and Evaluation.

McCubbin, D. R. and Delucchi, M. A. (1996). The Social Cost of Health Effects of Motor Vehicle Air Pollution. UCD-ITS-RR-96-3(11). Davis, CA: University of California, Institute of Transportation Studies. August.

McCubbin, D. R. and Delucchi, M. A. (1999). The health costs of motor vehicle related air pollution. Journal of Transport Economics and Policy 33, 253-286. 
Murphy, J. J. and Delucchi, M. A. (1998). A review of the literature on the social cost of motor vehicle use. Journal of Transportation and Statistics 1, 15-42.

Murphy, J. J., Delucchi, M. A., McCubbin, D. R. and Kim, J. (1999). The cost of crop damage caused by ozone air pollution from motor vehicles. Journal of Environmental Management 55, 273-289.

National Climatic Data Center (1991). 1990 Local Climatological Data. Asheville, NC.

Ozkaynak, H. et al. (1985). Relationships between aerosol extinction coefficients derived from airport visual range observations and alternative measures of airborne particle mass. Journal of the Air Pollution Control Association 35, 1176-1185.

Pope, C. A. et al. (1995). Particulate air pollution as a predictor of mortality in a prospective study of US adults. American Journal of Respiratory and Critical Care Medicine 151, 669-674.

Rabl, A. and Spadaro, J. V. (1999). Damages and costs of air pollution: an analysis of uncertainties. Environment International 25, 29-46.

Romilly, P. (1999). Substitution of bus for car travel in urban Britain: an economic evaluation of bus and car exhaust emission and other costs. Transportation Research D 4, 109-125.

Rosen, S. (1974). Hedonic prices and implicit markets: product differentiation in pure competition. Journal of Political Economy 82, 34-55.

Rotily, M., Tremolieres, L., Armengaud, A. and Charpin, D. (1999). Connaissances, opinions et attitudes des médecins face à la pollution atmosphérique dans les Bouches-du-Rhône. Revue des Maladies Respiratoires, 16, 575-84.

Schwartz, J. (2000). Harvesting and long term exposure effects in the relation between air pollution and mortality. American Journal of Epidemiology 151, 440-448.

Schwartz, J. 2001. Is there harvesting in the association of airborne particles with daily deaths and hospital admissions? Epidemiology 12, 55-61.

Schwing, R. C., Southworth, B. W., von Buseck, C. R. and Jackson, C. J. (1980). Benefit-cost analysis of automotive emission reductions. Journal of Environmental Economics and Management 7, 44-64.
Small, K. A. and Kazimi, C. (1995). On the costs of air pollution from motor vehicles. Journal of Transport Economics and Policy 29, 7-32.

Smith, V. K. (2000). JEEM and non-market valuation: 1974-1998. Journal of Environmental Economics and Management 39, 351-374.

Smith, V. K. and Huang, J. C. (1995). Can markets value air quality? a meta-analysis of hedonic property value models. Journal of Political Economy 103, 209-227.

Spadaro, J. V., Rabl, A., Jourdain, E. and Coussy, P. (1998). External costs of air pollution: case study and results for transport between Paris and Lyon. International Journal of Vehicle Design 20, 274-282.

Trijonis, J. (1982). Visibility in California. Journal of the Air Pollution Control Association 32, 165-169.

US Environmental Protection Agency (1993). Magnetic data tape of ambient air quality measurements of $\mathrm{CO}, \mathrm{NO}_{x}, \mathrm{O}_{3}, \mathrm{PM}_{2.5}, P M_{10}$, and TSP at all available monitoring sites in the United States 1988-1991. US Environmental Protection Agency, National Air Data Branch.

US Environmental Protection Agency (1997). The Benefits and Costs of the Clean Air Act, 1970 to 1990. EPA 410-R-97-002. Washington, DC: US Environmental Protection Agency, Office of Air and Radiation, and Office of Policy Analysis and Review. October.

US Environmental Protection Agency (1999). The Benefits and Costs of the Clean Air Act, 1990 to 2010. EPA 410-R-99-001. Washington, DC: US Environmental Protection Agency, Office of Air and Radiation, and Office of Policy Analysis and Review. November.

US Environmental Protection Agency (1998). National Air Quality and Emissions Trends Report 1996. EPA-454/R-97-013. Research Triangle Park, NC: US Environmental Protection Agency, Office of Air Quality Planning and Standards. January.

Watson, J. G. and Chow, J. C. (1994). Clear sky as a challenge for society. Annual Review of Energy and Environment 19, 241-266.

Yaari, M. (1965). Uncertain lifetime, life insurance, and the theory of the consumer. Review of Economic Studies 32, 137-150.

Zabel, J. E. and Kiel, K. A. (2000). Estimating the demand for air quality in four US cities. Land Economics 76, 174-194. 